\title{
Outcomes of Percutaneous Nephrolithotomy in Preschool Age Group: A Single-Center Study
}

\author{
Hakan Bahadir Haberal, MD, ${ }^{1}$ Hasan Serkan Dogan, ${ }^{2}$ Burak Citamak, MD, ${ }^{1}$ Berk Hazir, MD, ${ }^{1}$ \\ Mesut Altan, MD, ${ }^{1}$ Cenk Yucel Bilen, ${ }^{1}$ and Serdar Tekgul ${ }^{2}$
}

\begin{abstract}
Objective: To determine the factors affecting the outcomes of percutaneous nephrolithotomy (PCNL) in patients in infantile/toddler and preschool age group.

Materials and Methods: The data of 186 renal units from 152 patients who underwent PCNL were retrospectively analyzed. Patients under $\leq 72$ months of age were included in the study. The patients were divided into two groups according to their age: infantile/toddler and preschool group. Demographics and stone features were compared between infantile/toddler and preschool age groups. Effects of different factors on complications and stone-free rates were investigated. Comparisons in the study were done using SPSS 24.0 software for Windows.

Results: The mean age of the patients was $40.5 \pm 16.5$ months, and the female/male ratio was $87 / 99$. The median stone burden was $1.92 \mathrm{~cm}^{2}(0.12-20)$. Stone-free rates were $75.3 \%$ and $84.4 \%$ when cases with Clinically Insignificant Residual Fragments were also included. The numbers of patients with Clavien grade 1, grade 2, and grade $3 \mathrm{~b}$ complications were $7(3.8 \%), 39(21 \%)$, and 9 (4.8\%), respectively. There was no difference between infantile/toddler and preschool children in terms of stone-free and complication rates $(p=0.082$, $p=0.088$, respectively). Mini PCNL and tubeless - totally tubeless - urinary diversion techniques were more frequently performed in the infantile/toddler group compared to the preschool group $(p=0.001, p=0.028$, respectively). Presence of staghorn stone was the only significant factor for complications, while the number of stones was significant for stone-free rates for patients $\leq 72$ months $(p=0.012, p=0.001$, respectively). Stone burden was the only predictive factor for complications in patients aged $\leq 36$ months, while number of stones was predictive for success in patients aged between 37 and 72 months ( $p=0.034, p=0.006$, respectively).

Conclusion: PCNL is a feasible and effective method in preschool age group with acceptable complications and high success rates. Presence of staghorn stone is predictive for complications, while number of stones is predictive for success in the preschool age group.
\end{abstract}

Keywords: kidney calculi, pediatric urolithiasis, percutaneous nephrolithotomy, preschool children

\section{Introduction}

$\mathbf{I}$ N RECENT YEARS, it has been observed that there is a significantly increasing trend in the incidence of stone disease in the pediatric age group. ${ }^{1}$ Turkey is one of the endemic regions for pediatric stone disease. ${ }^{2}$ Metabolic abnormalities, anatomic disorders, environmental factors, and genetics play a role in stone formation in the pediatric age group. ${ }^{3}$

The first treatment option for most kidney stones in the pediatric age group is extracorporeal shockwave lithotripsy (SWL), while percutaneous nephrolithotomy (PCNL) is reserved for large and complex stones. ${ }^{2}$ The first series on pediatric age group PCNL using adult-size materials was reported by Woodside and colleagues in $1985 .{ }^{4}$ However, there were doubts that adult-size materials could cause renal damage in small kidneys. Therefore, the idea of miniaturization of endoscopic materials has emerged. The first mini PCNL series performed by $11 \mathrm{~F}$ access sheath in preschool age group was published by Jackman and colleagues in 1998. ${ }^{5}$ Subsequently, PCNL at younger ages and using miniaturized equipment have become increasingly common.

\footnotetext{
${ }^{1}$ Department of Urology, Hacettepe University School of Medicine, Ankara, Turkey.

${ }^{2}$ Division of Pediatric Urology, Department of Urology, Hacettepe University School of Medicine, Ankara, Turkey.
} 
In this study, we hypothesized that PCNL can be performed with high success and acceptable complication rates in preschool age group. As a secondary outcome, we aimed to determine the factors affecting complications and success in the preschool and infantile/toddler age group. To the best of our knowledge, this study is one of the largest series in the literature in this age group.

\section{Materials and Methods}

This study protocol was approved by the Hacettepe University Ethics Committee. The data of 186 renal units (RU) of 152 consecutive patients with adequate data who underwent PCNL between December 1997 and November 2019 were retrospectively analyzed. Patients under 6 years of age $(\leq 72$ months) were included in the study. Twenty-one patients were operated at two different, two patients at three different, and three patients at four different times.

All patients were evaluated with preoperative renal function tests, urinalysis, and urine culture. For preoperative imaging methods, kidney, ureter, and bladder radiograph (KUB), intravenous urography (IVU), ultrasonography (USG), and nonenhanced CT were used. Appropriate antibiotic treatment was administered according to the positive urine culture results. All procedures were performed in prone position. All renal accesses were performed with fluoroscopic guidance, and tract was dilated with Amplatz dilators. The primary surgeon decided the sheath diameter and surgical procedure according to the characteristics of the patient and the kidney stone. Blood transfusions were performed intraoperatively due to excessive bleeding or hemoglobin drop and changes in vital signs postoperatively and according to 7 to $10 \mathrm{~mL} / \mathrm{kg}$ formula.

For patients with nephrostomy postoperatively, antegrade pyelography was performed on postoperative second or third day; and after monitoring, the spontaneous passage to the bladder nephrostomy was clamped and removed. Patients without any urine leakage from the nephrostomy tract or fever were discharged. For patients with Double-J stent inserted postoperatively, stent was removed at the third or fourth week of the surgery. For patients with tubeless and totally tubeless PCNL, patients without any urine leakage from the access tract were discharged on postoperative day 1 . All patients were evaluated with KUB on postoperative day 1 to evaluate the localization of the nephrostomy or the Double-J stent and the presence of a significant residual fragment. Stone-free status was evaluated by urinary USG after at least postoperative fourth to sixth week.

Patients were classified into two groups according to their age as the infantile/toddler group (0-36 months) and the preschool group (37-72 months). The two groups were compared in terms of gender, stone burden $\left(\mathrm{cm}^{2}\right)$, number of stones (single or multiple), previous stone treatments (PCNL, SWL, multiple, or others), presence of staghorn stone, stone location in the kidney (renal pelvis, upper calices, middle calices, or lower calices), operation time (minutes), hospitalization time (days), postoperative hemoglobin change $(\mathrm{g} / \mathrm{dL})$, operation type (standard or mini PCNL), operation side, tract number (1 or 2), postoperative urinary diversion (nephrostomy, tubeless, or totally tubeless), success rates, and complications.

Clavien-Dindo classification was used to evaluate the complications. ${ }^{6}$ The procedures were categorized into two groups as standard PCNL and mini PCNL according to the sheath size used. ${ }^{7,8}$ We used a cutoff of $22 \mathrm{~F}$ for sheath size. ${ }^{9}$ We performed mini-PCNL through $14 \mathrm{~F}, 16 \mathrm{~F}$, or $17.5 \mathrm{~F}$ and standard PCNL through $24 \mathrm{~F}$ and $30 \mathrm{~F}$ sheaths. PCNL without postoperative nephrostomy tube placement was defined as tubeless, and PCNL with neither a nephrostomy tube nor a ureteral stent was defined as totally tubeless. Stones branching from renal pelvis to the two major calices were classified as staghorn. Complete clearance in postoperative imaging was accepted as success. Residual fragments $<4 \mathrm{~mm}$ were evaluated as clinically insignificant residual fragments (CIRFs) and considered as failure. ${ }^{10}$

Patients with calcium oxalate monohydrate and dihydrate stones were classified as calcium oxalate group; with struvite and ammonium urate were classified as infection group; and those with more than one stone type were classified as mixed. Calcium oxalate, cystine, calcium phosphate, infection, uric acid, hypoxanthine, and mixt stones were compared in terms of postoperative urinary tract infection (UTI) and stone-free rates.

All statistical analyses were performed using the SPSS 24.0 software for Windows. For univariate analysis, the chisquare test was used for nominal data, the $t$-test was used for parametric variables, and the Mann-Whitney U test was used for nonparametric variables. Mean \pm standard deviation is used for parametric variables, while median and range was used for nonparametric variables. Binary logistic regression analysis was used in multivariate analysis. $p<0.05$ was considered as the statistical significance level.

\section{Results}

The mean age of the patients at the time of surgery was $40.5 \pm 16.5$ months (5-72), and female to male ratio was $87: 99$. The median stone burden and mean operation were $1.92 \mathrm{~cm}^{2}$ (range: $0.12-20$ ) and $92.6 \pm 31.6$ minutes, respectively. The median follow-up period was 19 months (3-189). Eighty-three $(44.6 \%)$ patients underwent left side surgery, while $103(55.4 \%)$ underwent right side surgery. The number of patients of IVU, USG, and nonenhanced CT used for preoperative imaging was $48(25.8 \%), 22(11.8 \%)$, and 116 $(62.4 \%)$, respectively. The use of CT for preoperative imaging increased significantly after $2010(33.8 \%$ vs $78.8 \%, p<0.001)$.

Mini PCNL was performed in 86 patients (46.2\%), while standard PCNL in 100 patients $(53.8 \%)$. A total of $28 \mathrm{RU}$ (15.1\%) had staghorn stone, and $78(41.9 \%)$ had single stone. Of the $186 \mathrm{RU}, 4$ had (2.2\%) horseshoe kidney, 1 had $(0.5 \%)$ solitary kidney, and 1 had $(0.5 \%)$ duplicated system. Stonefree rates were $75.3 \%$ and $84.4 \%$ when CIRF cases were also included. Eighty-eight $(47.3 \%)$ patients had a previous stone treatment history. Of patients with single stone, $61.5 \%$ had renal pelvis, $3.8 \%$ had upper calix stones, $10.3 \%$ had middle calix stones, and $24.4 \%$ lower calix stones. Of the 186 PCNL procedures, $91.5 \%$ were performed with 1 puncture, while $8.5 \%$ were performed with 2 punctures.

For prolonged urine leak, Double-J stent insertion was performed in five patients $(2.7 \%)$, and ureterorenoscopy was performed in one patient $(0.5 \%)$ after nephrostomy removal. One patient underwent ureterocalicostomy after ureteral injury. Three patients (1.6\%) underwent re-PCNL, four $(2.2 \%)$ underwent SWL, and one $(0.5 \%)$ underwent retrograde intrarenal surgery for residual stones.

When we divided the patients into two groups according to age as infantile/toddler and preschool, gender, stone burden, 
presence of multiple stones, stone location (for patients with single stone), presence of staghorn stone, and previous stone treatment types were found to be similar between the groups $(p=0.135, p=0.275, p=0.174, p=0.698, p=0.156, p=0.567$, respectively) (Table 1 ).

Operation side, operation time, hospitalization time, tract number, and postoperative hemoglobin change were found to be similar between the groups $(p=0.429, p=0.551$, $p=0.222, p=0.389, p=0.146$, respectively). Mini PCNL and tubeless-totally tubeless-urinary diversion techniques were more frequently performed in the infantile/toddler group compared to the preschool group ( $p=0.001, p=0.028)$. Stone-free rates with and without CIRF were found to be similar between the infantile/toddler group and the preschool group ( $p=0.217, p=0.082$, respectively).

The numbers of patients with Clavien grade 1, grade 2 , and grade 3 b complications was 8 (4.3\%), 38 (20.4\%), and 9 (4.8\%), respectively. Although both complications and Clavien grade 3 complications were more common in the infantile/toddler group, the difference between the groups was not statistically significant $(p=0.088, p=0.377$, respectively). Twenty patients $(10.8 \%)$ required postoperative blood transfusion and 4 patients $(2.2 \%)$ required intraoperative blood transfusion, while there was no difference between the groups in terms of blood transfusion requirement $(p=0.071)$. Pneumothorax requiring chest tube drainage occurred in 1 case $(0.5 \%)$, and postoperative UTI developed in 16 cases $(8.6 \%)$; those were treated by appropriate parenteral antibiotics. There was no statistically significant difference be-

Table 1. Comparison of Demographic and Preoperative Characteristics Between Patients Ages $\leq 36$ and 37-72 Months

\begin{tabular}{|c|c|c|c|}
\hline & $\begin{array}{c}\text { Infantile/Toddler } \\
(\mathrm{N}=77, \\
41.4 \%)\end{array}$ & $\begin{array}{c}\text { Preschool } \\
(\mathrm{N}=109, \\
58.6 \%)\end{array}$ & $\mathrm{p}$ \\
\hline $\begin{array}{l}\text { Stone burden, } \mathrm{cm}^{2} \text {, } \\
\text { median (min-max) }\end{array}$ & $1.94(0.18-12)$ & $\begin{array}{c}1.91 \\
(0.12-20)\end{array}$ & 0.275 \\
\hline \multicolumn{4}{|l|}{ Gender, $\%$} \\
\hline Female & 40.3 & 51.4 & 0.135 \\
\hline Male & 59.7 & 48.6 & \\
\hline \multicolumn{4}{|l|}{ Number of stones, $\%$} \\
\hline Single stone & 37.7 & 47.7 & 0.174 \\
\hline Multiple stones & 62.3 & 52.3 & \\
\hline \multicolumn{4}{|c|}{ Previous stone treatment, $\%$} \\
\hline PCNL & 7.8 & 6.4 & 0.567 \\
\hline SWL & 15.6 & 19.3 & \\
\hline Others $^{\mathrm{a}}$ & 27.3 & 19.3 & \\
\hline \multicolumn{4}{|l|}{ Staghorn stone, $\%$} \\
\hline Yes & 19.5 & 11.9 & 0.156 \\
\hline No & 80.5 & 88.1 & \\
\hline \multicolumn{4}{|l|}{ Stone location, ${ }^{\mathrm{b}} \%$} \\
\hline Renal pelvis & 70.4 & 56.9 & 0.698 \\
\hline Upper caliceal & 3.7 & 3.9 & \\
\hline Middle caliceal & 7.4 & 11.8 & \\
\hline Lower caliceal & 18.5 & 27.5 & \\
\hline
\end{tabular}

${ }^{\mathrm{a} O p e n,}$ ureterorenoscopy, Double-J stent insertion, multiple interventions to same kidney.

${ }^{\mathrm{b}}$ For patients with single stone.

$\mathrm{PCNL}=$ percutaneous nephrolithotomy; $\mathrm{SWL}=$ extracorporeal shockwave lithotripsy. tween the groups in terms of postoperative UTI rates $(p=0.842)$ (Table 2).

Presence of staghorn stone and the number of stones were associated with complications in univariate analysis in patients aged $\leq 72$ months ( $p=0.010, p=0.021$, respectively) (Table 3). In multivariate analysis, presence of staghorn stone was found to be the only significant factor $(p=0.012)$ (Table 4). We carried out additional analyses to evaluate the factors affecting complications for patients aged $\leq 36$ months and between 37 and 72 months. Presence of staghorn stone and stone burden were found to be significant on univariate analysis in patients aged $\leq 36$ months, while only the stone burden was associated with complications on multivariate analysis ( $p=0.034, p=0.031, p=0.034$, respectively). None of the factors was associated with complications in patients aged between 37 and 72 months.

TABle 2. COMPARISON OF INTRAOPERATIVE and Postoperative Characteristics Between Patients Ages $\leq 36$ and 37-72 Months

\begin{tabular}{|c|c|c|c|}
\hline & $\begin{array}{c}\text { Infantile/Toddler } \\
(\mathrm{N}=77, \\
41.4 \%)\end{array}$ & $\begin{array}{l}\text { Preschool } \\
(\mathrm{N}=109, \\
58.6 \%)\end{array}$ & $\mathrm{p}$ \\
\hline $\begin{array}{l}\text { Operation time, } \\
\text { minutes, } \\
\text { mean } \pm S D\end{array}$ & $94.3 \pm 30.8$ & $91.4 \pm 32.2$ & 0.551 \\
\hline $\begin{array}{l}\text { Hospitalization time, } \\
\text { days, mean } \pm S D\end{array}$ & $5.38 \pm 4$ & $4.78 \pm 2.62$ & 0.222 \\
\hline $\begin{array}{l}\text { Hemoglobin } \\
\text { decrease, g/dL, } \\
\text { mean } \pm \mathrm{SD}\end{array}$ & $1.31 \pm 0.15$ & $1.02 \pm 0.12$ & 0.146 \\
\hline \multicolumn{4}{|l|}{ Operation type, \% } \\
\hline Standard & 39 & 64.2 & 0.001 \\
\hline Mini & 61 & 35.8 & \\
\hline \multicolumn{4}{|l|}{ Operation laterality, \% } \\
\hline Right & 51.9 & 57.8 & 0.429 \\
\hline Left & 48.1 & 42.2 & \\
\hline \multicolumn{4}{|l|}{ Tract number } \\
\hline 1 & 93.5 & 89.9 & 0.389 \\
\hline 2 & 6.5 & 10.1 & \\
\hline \multicolumn{4}{|l|}{ Success, \% } \\
\hline $\mathrm{SF}+\mathrm{CIRF}$ & 88.3 & 81.7 & 0.217 \\
\hline Residual fragment & 11.7 & 18.3 & \\
\hline \multicolumn{4}{|l|}{ Success, $\%$} \\
\hline Stone free & 81.8 & 70.6 & 0.082 \\
\hline Residual fragment & 18.2 & 29.4 & \\
\hline \multicolumn{4}{|l|}{ Complication, $\%$} \\
\hline Yes & 36.4 & 24.8 & 0.088 \\
\hline No & 63.6 & 75.2 & \\
\hline \multicolumn{4}{|l|}{ Blood transfusion, $\%$} \\
\hline Yes & 18.2 & 9.2 & 0.071 \\
\hline No & 81.8 & 90.8 & \\
\hline \multicolumn{4}{|c|}{ Postoperative urinary tract infection, $\%$} \\
\hline Yes & 9.1 & 8.3 & 0.842 \\
\hline No & 90.9 & 91.7 & \\
\hline \multicolumn{4}{|l|}{ Complication, \% } \\
\hline Clavien grade 3 & 6.5 & 3.7 & 0.377 \\
\hline Clavien $0-1-2$ & 93.5 & 96.3 & \\
\hline
\end{tabular}

Bold values indicate statistical significance.

$\mathrm{CIRF}=$ clinically insignificant residual fragment; $\mathrm{SD}=$ standard deviation; $\mathrm{SF}=$ stone-free. 
TABle 3. Univariate ANAlysis for FaCtors AfFecting Complications and Stone-Free Rates For Patients Ages $\leq 72$ Months

\begin{tabular}{|c|c|c|c|c|}
\hline & \multicolumn{2}{|c|}{ Complications } & \multicolumn{2}{|c|}{ Stone-free rates } \\
\hline & $\%$ & $\mathrm{p}^{\mathrm{a}}$ & $\%$ & $\mathrm{p}^{\mathrm{a}}$ \\
\hline $\begin{array}{l}\text { Operation side } \\
\text { Left } \\
\text { Right }\end{array}$ & $\begin{array}{l}28.9 \\
30.1\end{array}$ & 0.861 & $\begin{array}{l}75.9 \\
74.8\end{array}$ & 0.857 \\
\hline $\begin{array}{l}\text { Operation type } \\
\text { Conventional } \\
\text { Mini }\end{array}$ & $\begin{array}{l}27 \\
32.6\end{array}$ & 0.408 & $\begin{array}{l}77 \\
73.3\end{array}$ & 0.555 \\
\hline $\begin{array}{l}\text { Staghorn stone } \\
\text { Yes } \\
\text { No }\end{array}$ & $\begin{array}{l}50 \\
25.9\end{array}$ & 0.010 & $\begin{array}{l}53.6 \\
79.1\end{array}$ & 0.004 \\
\hline $\begin{array}{l}\text { Gender } \\
\text { Female } \\
\text { Male }\end{array}$ & $\begin{array}{l}28.7 \\
30.3\end{array}$ & 0.815 & $\begin{array}{l}81.6 \\
69.7\end{array}$ & 0.060 \\
\hline $\begin{array}{l}\text { Previous stone ti } \\
\text { Positive } \\
\text { Negative }\end{array}$ & $\begin{array}{l}\text { ment } \\
33 \\
26.5\end{array}$ & 0.338 & $\begin{array}{l}77.3 \\
73.5\end{array}$ & 0.548 \\
\hline $\begin{array}{l}\text { Number of stone } \\
\text { Single } \\
\text { Multiple }\end{array}$ & $\begin{array}{l}20.5 \\
36.1\end{array}$ & 0.021 & $\begin{array}{l}88.5 \\
65.7\end{array}$ & $<0.001$ \\
\hline $\begin{array}{l}\text { Stone burden, cn } \\
\quad<2 \\
\geq 2\end{array}$ & $\begin{array}{l}27.8 \\
30.7\end{array}$ & 0.671 & $\begin{array}{l}79.4 \\
71.6\end{array}$ & 0.217 \\
\hline $\begin{array}{l}\text { Tract number } \\
1 \\
2\end{array}$ & $\begin{array}{l}28.2 \\
43.8\end{array}$ & 0.194 & $\begin{array}{l}76.5 \\
62.5\end{array}$ & 0.231 \\
\hline
\end{tabular}

Bold values indicate statistical significance.

${ }^{a}$ Univariate analysis (chi-square test).

The number of stones and presence of staghorn stones were associated with stone-free rates in univariate analysis ( $p<0.001, p=0.004$, respectively) (Table 3 ). In multivariate analysis, the number of stones was determined as the only significant factor for success on multivariate analysis in patients aged $\leq 72$ months $(p=0.001)$ (Table 4$)$. When the same analysis was done for age groups, the number of stones and presence of staghorn stone were associated with success in patients aged between 37 and 72 months on univariate analysis, while only the number of stones was significant on multivariate analysis $(p=0.001, p=0.019, p=0.006$, respectively). None of the factors was associated with success for patients aged $\leq 36$ months.
When we divided the patients into two groups according to PCNL type as standard and mini PCNL, operation time, hospitalization time, stone-free rates, blood transfusion requirement, postoperative UTI rates, complications, and Clavien grade 3 complications were similar between groups $(p=0.112, \quad p=0.243, \quad p=0.555, \quad p=0.404, \quad p=0.463$, $p=0.408, p=0.565$, respectively). Patient age (43.4 months vs 37.1 months, $p=0.009)$ and stone burden $\left(3.13 \mathrm{~cm}^{2} v s\right.$ $1.97 \mathrm{~cm}^{2}, p=0.035$ ) were significantly higher in patients who underwent standard PCNL. When we evaluated chronologically (before $2010 \mathrm{vs}$ after 2010), there was a significant increase in the frequency of mini PCNL use after 2010 (16.2\% vs $63.6 \%, p<0.001)$.

Stone composition was available in 106 patients $(57 \%)$. The stone composition was calcium oxalate in 40 patients, cystine stones in 50 patients, struvite in 3 patients, ammonium urate in 1 patient, calcium phosphate in 1 patient, uric acid in 1 patient, hypoxanthine in 1 patient, and mixt in 9 patients. Stone-free rates were similar among different stone types $(p=0.171)$. Postoperative UTI rate was found to be significantly higher in patients with infection stones $(p<0.001)$.

\section{Discussion}

In recent years, there is an increase in the number of patients annually found to have renal stone disease in the pediatric age group. ${ }^{11,12}$ Kidney stones show high recurrence rates in the pediatric age group, and $\sim 50 \%$ of patients have symptomatic recurrence within 3 years. ${ }^{13}$ Considering the risk of anesthesia, it is important to achieve high stone-free rates after a single session of treatment in pediatric patients. SWL is mentioned as the first choice in most kidney stones, while PCNL is reserved for complex and large stones according to the current guideline recommendations. ${ }^{2} \mathrm{SWL}$ provides stone-free rates ranging from $47 \%$ to $60 \%$ after a single session of treatment, while stone-free rates ranging from $73.1 \%$ to $85.7 \%$ can be achieved by PCNL. ${ }^{14-19}$

Initially, one of the main concerns of PCNL in the pediatric age group was the risk of damage to kidney with adult-sized equipment. ${ }^{20}$ Therefore, PCNL was avoided in the preschool age group at first. Today, with the advances in technology, PCNL can be applied safely even in the infant age group. ${ }^{19}$ However, studies investigating PCNL results in preschool age in the literature are limited and small sized. ${ }^{19,21}$ For this reason, in our study, we investigated the factors affecting stone-free rates and complications after PCNL in the preschool age group. When we divided our study population into

Table 4. Multivariate Analysis for Factors Affecting Complications and Stone-Free Rates for Patients Ages $\leq 72$ Months

\begin{tabular}{lcccc}
\hline & \multicolumn{2}{c}{ Complications } & \multicolumn{2}{c}{ Stone-free rates } \\
\cline { 2 - 3 } & HR $(95 \%$ CI $)$ & $\mathrm{p}^{\mathrm{a}}$ & HR $(95 \%$ CI $)$ & $\mathrm{p}^{\mathrm{a}}$ \\
\hline Staghorn stone & $0.350(0.154-0.797)$ & $\mathbf{0 . 0 1 2}$ & $2.022(0.836-4.892)$ & 0.118 \\
Number of stones & $0.568(0.275-1.172)$ & 0.126 & $3.995(1.795-8.894)$ & $\mathbf{0 . 0 0 1}$ \\
\hline
\end{tabular}

Bold values indicate statistical significance.

${ }^{a}$ Multivariate analysis (binary logistic regression).

$\mathrm{CI}=$ confidence interval; $\mathrm{HR}=$ hazard ratio . 
two groups according to age as the infantile/toddler and preschool groups, there was no difference between the groups in terms of stone-free and complication rates. These findings suggest that PCNL can be safely performed in any age group.

Mini PCNL and tubeless diversion rates were significantly higher in the infantile/toddler group. The use of standard PCNL is an appropriate option in patients with high stone burden to reduce the duration of surgery and the associated anesthetic risk. In the younger age group, especially in infants and toddlers, considering the kidney sizes of this age group, mini PCNL should be considered as the primary option. The choice of instrument size depends on the availability, stone load, and the patient age, and it is an expected finding to be using smaller size instruments in younger age group. However, the surgeon should have the experience of making the balance between the advantages and disadvantages of the preferred instrument in terms of irrigation fluid drainage and renal parenchyma trauma.

PCNL is not a surgical procedure without complications. The complication rate was $29.6 \%$ in our series. Our complication rate was found to be similar to the studies in the literature. ${ }^{17,19,22}$ All our complications were Grade 3 and below according to Clavien-Dindo classification. In the study of Onal and colleagues, PCNL complication rate was found as $27.7 \%$, and they stated that the presence of partial staghorn stones and sheath size were predictive factors for complications. ${ }^{18}$ Similarly, in our series, the presence of staghorn stones was found to be the only predictive factor for complications in patients aged $\leq 72$ months. When we analyzed predictive factor for complications for age groups separately, we determined that stone burden was the only predictive factor for complications in the infantile/toddler group. We believe that the presence of staghorn stones has a role in complications due to creating the need for manipulation in the kidney and increasing the number of access tracts. In addition to this, we suppose that as the stone burden increases, the increase in the necessary manipulations in the kidney leads to a higher risk of damage especially in infantile/toddler kidney due to its less sheltered structure compared to older ones. Unlike Onal and colleagues, in our series, sheath size was not found to be related with complications. ${ }^{18}$ The fact that different classifications were made in the two studies according to sheath size may have played a role in this finding. In our study, age was observed to have no effect on complications and high-grade complications. This shows that PCNL can be safely applied in the infantile/toddler age group.

One of the common and worrying complications after PCNL is bleeding and blood transfusion requirement. ${ }^{23}$ The pediatric PCNL literature shows that transfusion rates range between $3.8 \%$ and $15.3 \% .^{17-19,22,24-26}$ In accordance with the literature, in our series, $12.9 \%$ of the patients required blood transfusion. In our series, transfusion rates were higher in the infantile/toddler group, although the difference did not reach statistical significance. Despite the availability of sheaths smaller than $20 \mathrm{~F}$, this caliber might still be large for an infant or toddler age group and as the age becomes younger the kidney becomes more mobile and ends up with difficult tract establishment that can cause bleeding more. It is important to perform dilatation procedure over a straight line under fluoroscopy without allowing the bending of the guidewire to overcome the renal mobility problem. In this age group, using single-step dilatation instruments can also be beneficial. Besides, using appropriate size instruments, limiting the duration of surgery to 2 hours, avoiding forceful manipulations with rigid instruments, planning staged surgery for patients with high stone burden, and using flexible nephroscope for stones in different localizations in kidney may be beneficial in reducing the risk of bleeding and blood transfusion in this age group. However, use of flexible instruments is not beneficial in presence of bleeding; therefore, decision of this maneuver should be given before the bleeding starts.

In our study, the rate of patients who underwent postoperative UTI was found to be $8.6 \%$. Other series in the literature report postoperative UTI rates differing between $3.5 \%$ and $6 \%$, which are similar to our series. ${ }^{24,25}$ Kaygisiz and colleagues stated young age as a predictive factor for UTI development. $^{25}$ On the contrary, in our study, no difference was observed between the infantile/toddler group and the preschool group in terms of UTI rates. One explanation for this difference may be the use of different criteria for the classification of the age groups.

Six of our nine patients with grade 3 complications were composed of those who underwent Double-J stent insertion (five patients) and ureterorenoscopy (one patient) due to prolonged urine leak. In one patient after returning to the supine position at the end of the surgery, abdominal distention was observed. Upon examination, distention was found to have occurred due to the extravasation of irrigation fluid. Drainage catheter was placed in the patient, and he was discharged without any problems during follow-up. Intraabdominal irrigation fluid extravasation after PCNL is a rare complication but could be life threatening. Few publications in the literature contain this complication. ${ }^{27}$ It is thought that higher intrarenal pressure due to smaller access tracts further increases the risk of perforation and extravasation. ${ }^{23}$ The occurrence of extravasation during mini PCNL in our patient supports this idea. Abdominal examination should be performed under anesthesia before completion of the surgery. Intraoperative USG can be used in suspected cases for this purpose. Adjacent organ injuries are rare after PCNL, and the most commonly injured organs are the lungs and pleura. ${ }^{23} \mathrm{It}$ is known that the risk of intrathoracic complications is significantly increased in patients undergoing supracostal access. ${ }^{28}$ Our single case of pneumothorax was a 5-month-old male who underwent right side mini PCNL with supracostal access. Pneumothorax was detected in the postoperative period, and the patient was followed up by chest tube drainage and then discharged without any problems. While collecting system injuries during PCNL can be seen in as much as $7 \%$ of patients in the adult age group, it is a rare complication in the pediatric age group. ${ }^{18,23,27}$ In one patient with prolonged urine leak after nephrostomy removal, damage was detected in the ureteropelvic junction while trying to insert a Double-J stent. The patient was followed up by percutaneous nephrostomy, and ureterocalicostomy was later performed. Currently, the patient is followed without any problems. In conclusion, complications of pediatric PCNL were mostly low grade and could be managed conservatively.

In the present study, primary stone-free rate was $75.3 \%$. Examining the prospective follow-up of CIRFs in pediatric patients, it is seen that residues have become symptomatic in $\sim 1 / 3$ of the patients. ${ }^{29}$ For this reason, in our study, complete stone-free status was accepted as the criterion of success, and 
cases with CIRF were evaluated as unsuccessful. Compared to other series in the literature, this rate is seen to be slightly lower. ${ }^{19,22}$ The factors that caused this difference were thought to be the higher number of patients with multiple stones and staghorn stones in our study population compared to other series. In accordance with the literature, we observed the presence of multiple stones as a determinative factor for success. Similarly, in the mini PCNL series of Daw and colleagues, a number of stones $>2$ was shown to be effective on both primary and secondary stone-free rates. ${ }^{19}$ We think that the tendency to avoid difficult manipulations and multiple accesses for stones located in different localizations in the kidneys of pediatric patients has an effect on low stone-free rates after PCNL in patients with multiple stones. Therefore, it would be beneficial to inform the families of children with multiple stones that additional treatment may be needed before PCNL.

When stone compositions were evaluated in our study population, cystine stones were found in approximately half of our patients. Cystinuria is caused by an autosomal recessive disorder characterized by amino acid reabsorption failure. ${ }^{2}$ It is stated that cystine stones are onset at an earlier age and can reach larger sizes. ${ }^{30}$ The fact that our study population consisted of PCNL patients at preschool age may have an effect on this uncommon high cystine stone ratio considering these features of cystine stones.

The main limitation of our study was the retrospective nature and the coverage of over 20 years. Over the years, there have been changes in radiologic imaging methods and surgical procedures. Since CT was not performed on all patients preoperatively, other imaging methods were used to calculate the stone burden in some patients. Besides, it has been found that a significant increase in CT usage for preoperative imaging was observed when the patients were chronologically evaluated in our study population. Patients' body mass indexes, fluoroscopy times, and kidney access locations could not be evaluated in the study due to an absence of data. The use of USG for postoperative stone-free status may be considered as another limitation and can be a subject of discussion as it can fail to detect the small postoperative residual fragments. However, a second CT within postoperative 2 months for detection of residual fragments is an overdiagnostic tool for a child who underwent a prior CT for preoperative evaluation. Therefore, we reserve this modality for complicated or doubtful cases.

\section{Conclusions}

PCNL is a feasible and effective method in the preschool age group with acceptable complications and high success rates. Complications are low grade, and most can be managed conservatively. As the patient age decreases, the rates of miniaturized and tubeless PCNL increase. Presence of staghorn stone is predictive for complications, while the number of stones is predictive for success in the preschool age group.

\section{Author Disclosure Statement}

No competing financial interests exist.

\section{Funding Information}

No funding was received for this article.

\section{References}

1. Hernandez JD, Ellison JS, Lendvay TS. Current trends, evaluation, and management of pediatric nephrolithiasis. JAMA Pediatr 2015;169:964-970.

2. Radmayr C, Bogaert G, Dogan HS, et al. EAU Guidelines on Paediatric Urology presented at the EAU Annual Congress Barcelona 2019. Arnhem, The Netherlands: EAU Guidelines Office, 2019.

3. Bowen DK, Tasian GE. Pediatric stone disease. Urol Clin North Am 2018;45:539-550.

4. Woodside JR, Stevens GF, Stark GL, Borden TA, Ball WS. Percutaneous stone removal in children. J Urol 1985;134: 1166-1167.

5. Jackman SV, Hedican SP, Peters CA, Docimo SG. Percutaneous nephrolithotomy in infants and preschool age children: Experience with a new technique. Urology 1998; 52:697-701.

6. Dindo D, Demartines N, Clavien PA. Classification of surgical complications: A new proposal with evaluation in a cohort of 6336 patients and results of a survey. Ann Surg 2004;240:205-213.

7. Kamal W, Kallidonis P, Kyriazis I, Liatsikos E. Minituriazed percutaneous nephrolithotomy: What does it mean? Urolithiasis 2016;44:195-201.

8. Schilling D, Husch T, Bader M, et al. Nomenclature in PCNL or The Tower Of Babel: A proposal for a uniform terminology. World J Urol 2015;33:1905-1907.

9. Rassweiler J, Rassweiler MC, Klein J. New technology in ureteroscopy and percutaneous nephrolithotomy. Curr Opin Urol 2016;26:95-106.

10. Ozdedeli K, Cek M. Residual fragments after percutaneous nephrolithotomy. Balkan Med J 2012;29:230-235.

11. Routh JC, Graham DA, Nelson CP. Epidemiological trends in pediatric urolithiasis at United States freestanding pediatric hospitals. J Urol 2010;184:1100-1104.

12. Sas DJ, Hulsey TC, Shatat IF, Orak JK. Increasing incidence of kidney stones in children evaluated in the emergency department. J Pediatr 2010;157:132-137.

13. Tasian GE, Kabarriti AE, Kalmus A, Furth SL. Kidney stone recurrence among children and adolescents. J Urol 2017;197:246-252.

14. Citamak B, Altan M, Bozaci AC, et al. Percutaneous nephrolithotomy in children: 17 years of experience. J Urol 2016;195(Pt 1):1082-1087.

15. Dogan HS, Altan M, Citamak B, et al. A new nomogram for prediction of outcome of pediatric shock-wave lithotripsy. J Pediatr Urol 2015;11:84.e1-e6.

16. Alsagheer G, Abdel-Kader MS, Hasan AM, et al. Extracorporeal shock wave lithotripsy (ESWL) monotherapy in children: Predictors of successful outcome. J Pediatr Urol 2017;13:515.e1-e5.

17. Bilen CY, Gunay M, Ozden E, et al. Tubeless mini percutaneous nephrolithotomy in infants and preschool children: A preliminary report. J Urol 2010;184:24982502.

18. Onal B, Dogan HS, Satar N, et al. Factors affecting complication rates of percutaneous nephrolithotomy in children: Results of a multi-institutional retrospective analysis by the Turkish pediatric urology society. J Urol 2014;191: 777-782.

19. Daw K, Shouman AM, Elsheemy MS, et al. Outcome of mini-percutaneous nephrolithotomy for renal stones in infants and preschool children: A prospective study. Urology 2015;86:1019-1026. 
20. Schuster TK, Smaldone MC, Averch TD, Ost MC. Percutaneous nephrolithotomy in children. J Endourol 2009;23: 1699-1705.

21. Yan X, Al-Hayek S, Gan W, et al. Minimally invasive percutaneous nephrolithotomy in preschool age children with kidney calculi (including stones induced by melaminecontaminated milk powder). Pediatr Surg Int 2012;28: 1021-1024.

22. Dogan HS, Kilicarslan H, Kordan Y, Celen S, Oktay B. Percutaneous nephrolithotomy in children: Does age matter? World J Urol 2011;29:725-729.

23. Wollin DA, Preminger GM. Percutaneous nephrolithotomy: Complications and how to deal with them. Urolithiasis 2018;46:87-97.

24. Ozden E, Mercimek MN, Yakupoglu YK, Ozkaya O, Sarikaya S. Modified Clavien classification in percutaneous nephrolithotomy: Assessment of complications in children. J Urol 2011;185:264-268.

25. Kaygisiz O, Satar N, Gunes A, et al. Factors predicting postoperative febrile urinary tract infection following percutaneous nephrolithotomy in prepubertal children. J Pediatr Urol 2018;14:448 e1-e7.

26. Senocak C, Ozbek R, Bozkurt OF, Unsal A. Predictive factors of bleeding among pediatric patients undergoing percutaneous nephrolithotomy. Urolithiasis 2018;46:383-389.

27. Guven S, Istanbulluoglu O, Gul U, et al. Successful percutaneous nephrolithotomy in children: Multicenter study on current status of its use, efficacy and complications using Clavien classification. J Urol 2011;185:1419-1424.

28. Lojanapiwat B, Prasopsuk S. Upper-pole access for percutaneous nephrolithotomy: Comparison of supracostal and infracostal approaches. J Endourol 2006;20:491-494.
29. El-Assmy A, El-Nahas AR, Harraz AM, et al. Clinically insignificant residual fragments: Is it an appropriate term in children? Urology 2015;86:593-598.

30. Sfoungaristos S, Hakim R, Katz R, et al. Cystine stones: A single tertiary center experience. J Endourol 2015;29: 362-366.

Address correspondence to: Hakan Bahadir Haberal, MD Department of Urology Hacettepe University School of Medicine

Altındag

Ankara 06230

Turkey

E-mail: bahadirhaberal@gmail.com

$\begin{aligned} & \quad \text { Abbreviations Used } \\ & \mathrm{CI}=\text { confidence interval } \\ & \mathrm{CIRF}=\text { clinically insignificant residual fragment } \\ & \mathrm{CT}=\text { computed tomography } \\ & \mathrm{HR}=\text { hazard ratio } \\ & \mathrm{IVU}=\text { intravenous urography } \\ & \mathrm{KUB}=\text { kidney, ureter, and bladder radiograph } \\ & \mathrm{PCNL}=\text { percutaneous nephrolithotomy } \\ & \mathrm{RU}=\text { renal units } \\ & \mathrm{SD}=\text { standard deviation } \\ & \mathrm{SF}=\text { stone-free } \\ & \mathrm{SWL}=\text { extracorporeal shockwave lithotripsy } \\ & \mathrm{UTI}=\text { urinary tract infection }\end{aligned}$

